\title{
DO BUNDESVERFASSUNGSGERICHT AO STF: A PONDERAÇÃO DE PRINCÍPIOS E AS NOÇÕES CONFUSAS
}

\author{
Gabriel Santos Rios ${ }^{1}$ e Eduardo Chagas Oliveira ${ }^{2}$ \\ 1. Estagiário PEVIC/UEFS, Graduando em Direito, Universidade Estadual de Feira de Santana, e-mail: \\ gabrielsrios@outlook.com \\ 2. Orientador, Departamento de Ciências Humanas e Filosofia, Universidade Estadual de Feira de Santana, e-mail: \\ echagas@uefs.br
}

PALAVRAS-CHAVE: ponderação de princípios; noções confusas; princípios constitucionais.

\section{INTRODUÇÃO}

A expansão da jurisdição constitucional é uma das notas distintivas do constitucionalismo contemporâneo. Nesse contexto, torna-se especialmente relevante investigar os modos de racionalização e controle das decisões judiciais, tendo em vista o alto grau de vagueza e ambiguidade de parte significativa dos textos constitucionais.

No Brasil, o Supremo Tribunal Federal tem utilizado frequentemente a regra da proporcionalidade desenvolvida pelo jurista alemão Robert Alexy (2011) no exercício do controle de constitucionalidade, como critério de fundamentação da sua ingerência contramajoritária de "guarda da Constituição" (art. 102, da Constituição Federal).

Conforme levantamento realizado por Fausto Santos de Morais (2013), o "princípio" da proporcionalidade foi invocado pelo STF em 189 decisões entre 7 de julho de 2002 e 7 de julho de 2012, dentre as quais estão leading cases do Tribunal, como o "caso Ellwanger" (HC 82.424/RS), mostrando o destaque qualitativo e quantitativo assumido pela teoria no Tribunal.

A regra da proporcionalidade (ALEXY, 2011) funcionaria como uma baliza para o exercício da jurisdição constitucional e para a pretensão de correção ínsita ao Direito, dotando os princípios constitucionais de eficácia irradiante, mas limitando o julgador com um procedimento bem delimitado a ser seguido ao decidir.

Indagada a constitucionalidade de um ato normativo, o "teste" da proporcionalidade exige que se atendam condições previamente delineadas. Primeiramente, examina-se a adequação, que está relacionada à aptidão do ato questionado, para realizar a finalidade constitucionalmente resguardada a que visa.

A segunda fase - ou dimensão - é a da necessidade, onde o exame desloca-se para a perquirição de uma medida menos restritiva a direitos fundamentais do que o ato em questão, mas capaz de realizar o mesmo objetivo com, pelo menos, idêntico grau de eficiência.

A proporcionalidade em sentido estrito (também chamada de ponderação, sopesamento ou balancing de princípios) é a terceira dimensão da regra da proporcionalidade e almeja a superar a colisão de princípios que fundamentam o ato normativo questionado, verificando se o grau de satisfação de um princípio justifica a não-satisfação de outro.

A pesquisa tem como objeto essa última fase, mediante a investigação da ponderação de princípios, nos moldes propostos por Robert Alexy (2011), sob a perspectiva da Teoria da Argumentação de Chaïm Perelman (1996, 2000), especialmente no que tange à teoria das noções confusas e à racionalização da avaliação de valores.

O tema está, portanto, diretamente conectado ao problema do modo e dos fóruns de tomada de decisões em um Estado de Direito constitucional e democrático, onde o emprego argumentativo irrefletido de princípios jurídicos pode significar tanto a erosão da normatividade constitucional quanto o bloqueio da atividade político-representativa.

A perspectiva de análise escolhida (a Teoria da Argumentação de Chaïm Perelman) é justificada pela relativa coincidência entre os princípios jurídicos e as noções confusas, como 
topoi com sentido indeterminado, cuja mobilização argumentativa é tanto necessária quanto potencialmente perniciosa.

Nota-se, ainda, a pertinência dos escritos do autor belga-polaco a respeito da possibilidade de racionalização da avaliação de valores (PERELMAN, 1996) com a consideração dos princípios como mandamentos de otimização judicialmente ponderáveis, proposta por Robert Alexy (2011).

A pesquisa permite, assim, uma reflexão crítica a respeito da racionalidade e da conformidade com o sistema democrático da ponderação de princípios, podendo ser considerada um instrumento de controle social do modo de decidir do STF e de fiscalização da força normativa da Constituição Federal de 1988.

\section{MATERIAL E MÉTODOS OU METODOLOGIA (ou equivalente)}

Trata-se de uma pesquisa que transita entre a Filosofia do Direito e a Teoria do Direito, amparada na investigação de conceitos (a exemplo de "princípios"), o que torna a pesquisa bibliográfica o método mais adequado para alcançar seus objetivos, mediante uma revisão de literatura centrada nas obras de Robert Alexy $(2001,2011)$ e Chaïm Perelman (1996, 2000).

\section{RESULTADOS E/OU DISCUSSÃO (ou Análise e discussão dos resultados)}

Chaïm Perelman (1996, 2000) e Robert Alexy $(2001,2011)$ partem de um mesmo ponto de partido no que tange à teoria da decisão judicial: a possibilidade de decidir racionalmente os casos jurídicos, no âmbito de uma concepção prático-argumentativa de racionalidade que não se confunde com aquela de caráter lógico-formal.

A ponderação de princípios, conforme proposta pelo autor alemão (ALEXY, 2011) leva em consideração inúmeras variáveis relacionadas à importância abstrata e concreta dos princípios em questão, além da confiabilidade das premissas empíricas e normativas que embasam os juízos acerca da realização desses princípios e da interferência neles.

Nesse sentido, a teoria de Alexy (2011) tem sido criticada (MORAIS, 2013) por não estabelecer qualquer limitação real à atividade dos juízes, uma vez que, com diferentes mobilizações das variáveis envolvidas na ponderação de princípios, chegar-se-ia a qualquer decisão para um determinado caso concreto.

Essas críticas são, em parte, procedentes, mas não devem levar ao abandono da teoria dos direitos fundamentais de Robert Alexy (2011), que pode ser adaptada com o auxílio de alguns elementos da Teoria da Argumentação de Chaïm Perelman (1996, 2000), cuja aplicabilidade ao âmbito jurídico pode ser justificada com o recurso à tese alexyana de que o direito é um caso especial do discurso prático geral (ALEXY, 2001).

Perelman (1996) aponta que a argumentação (jurídica ou não) não prescinde da utilização de noções confusas, que são "termos carregados de sentido emotivo" (PERELMAN, 1996, p. 11) e que, por isso, embora sejam pontos de partida comuns entre os interlocutores, provocam discussões sobre seu sentido e sua referência.

Embora não exista relação estrutural entre as noções confusas e os princípios enquanto mandamentos de otimização, existe uma coincidência significativa entre as duas categorias: justiça, dignidade, democracia, liberdade, segurança, todas são noções confusas e princípios jurídicos, compartilhando, portanto, as mesmas dificuldades associadas à sua mobilização em um raciocínio e exercendo as mesmas funções.

Isso significa que as noções confusas são, em geral, um ponto de partida comum (acordo) indispensável ao início de qualquer exercício argumentativo com pretensões de êxito, "o que não impede desacordos sobre casos de aplicação, quando se trata de passar dos valores comuns aos comportamentos concretos que deveriam guiar" (PERELMAN, 1996, p. 151). 
Aproveitando-se do hiato entre a adesão à noção confusa e a sua aplicação, há a técnica retórica da definição persuasiva, onde o teor valorativo positivo de uma noção confusa (geralmente, incontroverso) é mantido, enquanto o seu sentido conceitual (geralmente, controverso) é modificado à luz das intenções daquele que a mobiliza em um argumento.

As definições persuasivas podem ser utilizadas na argumentação jurídica, conforme reconhece o próprio Perelman (1996), o que pode levar à densificação argumentativa de princípios como a liberdade, a justiça social e a dignidade da pessoa humana em qualquer sentido pretendido pelos agentes jurídicos, justificando, com aparência de juridicidade, qualquer decisão judicial.

Alexy (2014) incorpora as dificuldades associadas à utilização das noções confusas na argumentação jurídica à sua teoria da decisão judicial em termos de confiabilidade das premissas empíricas e normativas mobilizadas para justificar a decisão sobre o peso concreto de um princípio em face a outro colidente, em conformidade com a mencionada lei do sopesamento.

O autor rejeita, entretanto, que uma decisão possa ser considerada preferível em relação a outra pelo simples fato de ser advinda de representantes democraticamente eleitos (legislador), sustentando, ainda, que mesmo as regras constitucionais não escapam ao exame da proporcionalidade e, consequentemente, à ponderação de princípios.

A exposição de Perelman (1996) acerca do uso e do abuso das noções confusas na argumentação aponta para a necessidade de precauções em sua utilização no âmbito jurídico, mas acaba por reconhecer que "não se dispõe de critérios objetivos na matéria" (PERELMAN, 1996, p. 683).

No âmbito da teoria dos direitos fundamentais de Robert Alexy (2011), contudo, há boas razões para propor ao menos um critério que permitiria identificar o abuso das noções confusas: a superação de regras constitucionais através da ponderação de princípios.

As regras são, para Alexy (2011), mandamentos de definição. O caráter constitucional das regras atribui-lhes, ainda, a qualidade de vinculação de todos os Poderes. Sendo assim, sob risco de diluir as fronteiras entre a atuação da autoridade responsável por ser "guardiã da Constituição" e o próprio parâmetro do controle a ser realizado, deve-se reconhecer o caráter imponderável das regras constitucionais, criando uma presunção absoluta de abusividade em caso de sua superação.

Isso não implica, ressalve-se, a univocidade na interpretação das regras constitucionais, que são, como qualquer outra formulação em linguagem natural, aptas a provocar divergências razoáveis em torno de seu sentido e alcance, vedando apenas a criação de uma nova regra (incompatível) mediante a ponderação de princípios.

\section{REFERENCIAS}

ALEXY, Robert. Formal principles: Some replies to critics. International Journal Of Constitutional Law, [s.1.], v. 12, n. 3, p.511-524, 1 jul. 2014.

ALEXY, Robert. Teoria da Argumentação Jurídica. São Paulo: Landy, 2001.

ALEXY, Robert. Teoria dos Direitos Fundamentais. 2. ed. São Paulo: Malheiros, 2011.

MORAIS, Fausto Santos de. Hermenêutica e pretensão de correção: uma revisão crítica da aplicação do princípio da proporcionalidade pelo Supremo Tribunal Federal. 2013. 346 f. Tese (Doutorado) - Curso de Direito, Universidade do Vale do Rio dos Sinos, São Leopoldo, 2013.

PERELMAN, Chaïm. Ética e Direito. São Paulo: Martins Fontes, 1996.

PERELMAN, Chaïm. Lógica Jurídica. São Paulo: Martins Fontes, 2000. 